
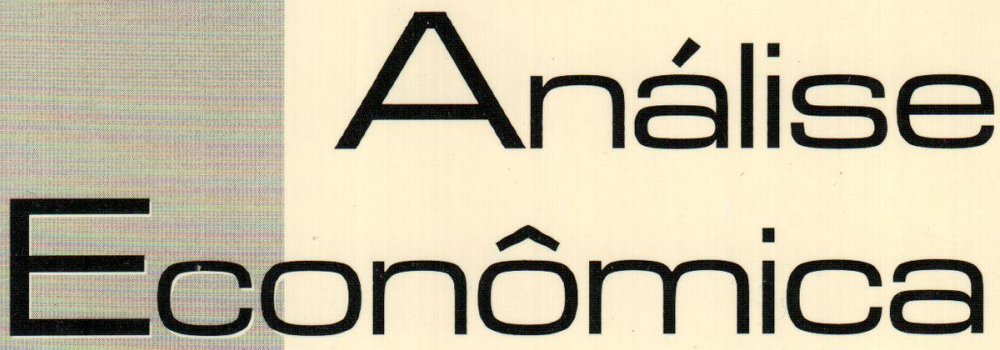

FATOS ESTHLIZADOS E CORRELAÇÁ O NO SETOR BANCÁRIO BRASILEIRO

IGOR AlexandRe C. DE MORAES

Política Monetária, Expectativas e Derivativos: uma ANALISE DO BRASIL PERIODO 1995-98

ROGERIO SOBREIRA

O FEDERAL RESERVE EM DOIS MOMENTOS DISTINTOS: ATUAÇÃO NA GRANDE DEPRESSÃO E NO FINAL DOS ANOS 1990

ROBSON RODRIGUES PEREIRA

BASHLÉIA 2 E ECONOMIAS EMERGENTES: UMA ABORDAGEM MÉDIA-VARIÁNCIA

otaViano Canuto e ANTÓ Nio josé MEIRELLES

VULNERABILIDADES EXTERNAS E INTERNAS DAS ECONOMIAS EMERGENTES E PADRÁ O DE CONTÁ GIO. A EXPERIÉnCIA DA DECADA DE 90

MiLTON PEREIRA OE ASSIS

ENDIVIDAMENTO PÚ BLICO E IMPACTO SOBRE FLUXOS DE CAPITAIS, RISCO-PAIS DIFERENCIAL DE JUROS NO BRASIL (1995-2002): MODELO VAR E TESTES DE CAUSALIDADE FLÁ VIO VILELA VIEIRA

METAS SOCIAIS DE PROCRAMAS DE MICROCRÉ DITO FINANCEIRAMENTE VIÁ VEIS

FERNANDO BATISTA PEREIRA E MARCO CROCCO

Estrutura Produtiva e Performance econó mica das ECONOMIAS ESTAdUAIS BRAsILIRAS NA DECADA DE NOVENTA ADELAR FOCHEZATTO

HISTORIA ECONO MICA Y TEORIA ECONO MICA: ENCUENTROS Y DESENCUENTROS

Gabriel PorciLe

EM BUSCA DA NOÇÃ O EVOLUCIONÁRIA (NEO-

SHUMPETERIANA) DO AUTO-INTERESSE DOS AGENTES: UMA CONTRIBUIÇAO A PARTIR DA LITERATURA SOBRE COOPERAÇÁO INTERFIRMAS

ROBSON ANTONIO GRASS

PRINCiPIOS E APULAÇó Es de REGRESSÁo Local ADALMIR MARQUETTI E LORI VIAL

globalizaçáo, Crescimento e pobreza, a Visäo do BANCO MUNDIAL SOBRE OS EFETTOS DA GLOBALIZAÇÁO NALI DE JESUS DE SOUZA

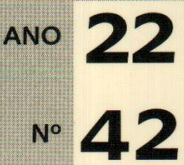




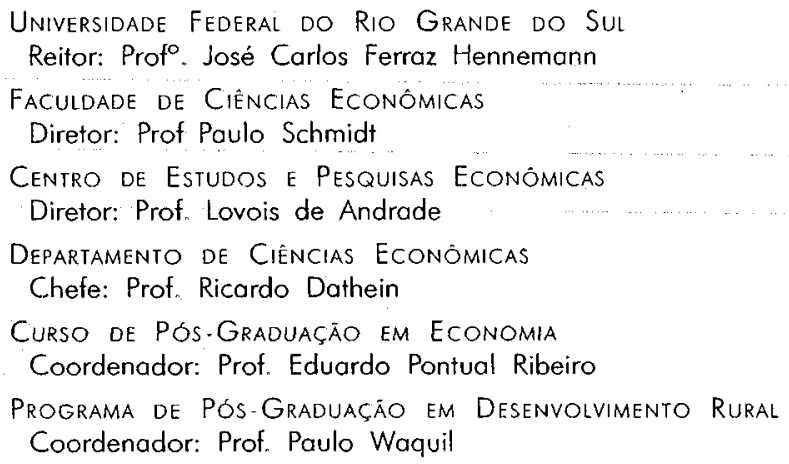

CONSELHO EDITORIAL:

André M. Cunha (UFRGS), Carlos G. A. Mieliz Netto (UFRGS), Carlos H. Hom (UFRGS), Eduardo $A_{n}$ Maldonado Filho (UFRGS), Eduardo P. Ribeiro (UFRGS), Eleutério F. S. Prado (USP), Eugênio Lagemann (UFRGS), Fernando Cardim de Carvalho (UFRJ), Fernando Ferrari Filho (UFRGS), Fernando de Holanda Barbosa (FGV/RJ), Flávio Vasconcellos Comim (UFRGS), Flávio A. Ziegelman (UFRGS), Gentil Corazza (UFRGS), Giácomo Balbinotto Netto (UFRGS), Gilberto de O. Kloeckner(UFRGS), Gustavo Franco (PUC/RJ), Hélio Henkin (UFRGS), Jairo L. Procianoy (UFRGS), Jan A. Kregel (UNCTAD), João Rogério Sanson (UFSC), Joaquim Pinto de Andrade (UnB), Jorge Paulo Araújo (UFRGS), José R. Iglesias (UFRGS), Júlio C. Oliveira (UFRGS), Luis P. Nogueról (UFGS), Luiz E. Faria (UFRGS), Marcelo S. Portugal (UFRGS), Maria Alice Lahorgue (UFRGS), Octávio A. C. Conceição (UFRGS), Orlando Martinelli (UFRGS), Paul Davidson (University of Tennessee), Paulo D. Waquil (UFRGS), Paulo Schmidt (UFRGS), Pedro C. D. Fonseca (UFRGS), Philip Arestis (University of Cambridge), Ricardo Dathein (UFRGS), Roberto C. de Moraes (UFRGS), Ronald Otto Hillbrecht (UFRGS), Sérgio M. M. Monteiro (UFRGS), Sabino da Silvo Porto Jr. (UFRGS), Stefano Florissi (UFRGS) e Werner Baer (University of Illinois at Urbana-Champaign).

COMISSÃO EDITORIAL:

Eduardo Augusto Maldonado Filho, Fernando Ferrari Filho, Gentil Corazza, Marcelo Savino Portugal, Paulo Dabdab Waquil e Roberto Camps Moraes.

EDITOR: Prof. Fernando Ferrari Filho

Egitor Adunto: Prof Gentil Corazza

Secretário: Paulo Roberto Eckent

REVISÁO DE TEXTOS: Vanete Ricacheski

Eottoraçáo Eletrónca: Nucleo de criação e editoraçáo Gráfica UFrgs: leonardo ponso Fundador: Prof. Antônio Carlos Santos Rosa

Os materiais publicados na revista Análise Econômica são da exclusiva responsabilidade dos autores. É permitida a reprodução total ou parcial dos trabalhos, desde que seja citada a fonte. Aceita-se permuta com revistas congêneres. Aceitam-se, também, livros para divulgação, elaboração de resenhas e recensōes Toda correspondência, material para publicação (vide normas na terceira capa), assinaturas e permutas devem ser dirigidos ao seguinte destinatário:

PROF. FERNANDO FERRAR! FILHO

Revista Análise Econômica - Av. João Pessoa, 52 CEP 90040-000 PORTO ALEGRE - RS, BRASIL Telefones: (051) 316-3513 - Fax: (051) 316-3990

Análise Econömíca E-mail: rae@ufrgs.br

Ano 22, $n^{\circ} 42$, morço, 2004 - Porto Alegre

Faculdade de Ciências Econômicas, UFRGS, 2004

Periodicidade semestral, março e setembro.

Tiragem: 500 exemplares

1. Teoria Econômica - Desenvolvimento Regional -

Economia Agrícola - Pesquisa Teórica e Aplicada.

Periódicos. 1. Brasil.

Faculdade de Ciências Econômicas,

Universidade Federal do Rio Grande do Sul. 


\title{
Basiléia 2 e economias emergentes: uma abordagem média-variância
}

\author{
Otaviano Canuto ${ }^{1}$ e Antônio José Meirelles ${ }^{2}$
}

Resumo: O presente texto aborda algumas das implicações, para as economias emergentes, contidas na atual proposta de reformulação do Acordo de Capital da Basiléia. O trabalho propõe-se a utilizar uma versão simplificada da clássica análise de média-variância de seleção de portfólios, como referência, para examinar algumas das proposições que têm sido formuladas no corrente debate sobre o que vem se convencionando chamar de "Basiléia 2" ou "Novo Acordo de Capital". O foco se dirigirá às duas orientaçōes gerais mostradas no esboço de Basiléia 2: a maior sensibilidade a riscos na nova versão do "enfoque padronizado" de requisitos de capital para riscos de crédito e o uso de modelos de "Valor sob Risco" (Value at Risk - VaR) que deverá acompanhar o estímulo aos "enfoques com base em classificações internas de risco" (IRB). O objetivo é analisar o argumento de alguns analistas que têm apontado tais modificações como tendencialmente endurecedoras das condições de acesso de economias em desenvolvimento às finanças globais.

Palavras-chave: Basiléia 2, Novo Acordo de Capitais, regulação bancária, economias emergentes.

Abstract: This paper approaches some of the implications to emerging economies which can already be extracted from the changes in the Basle Capital Accord proposed recently by the Basle Committee. We use a simplified version of the classical mean-variance analysis of portfolio selection, in order to examine some of the issues raised within the current debate on "Basle 2" or the "New Capital Accord". Focus is directed towards the two main guidelines followed in the reform design as displayed by the Basle Committee in January, 2001, namely, a higher risk sensitivity in a new version of the "standardized approach" to capital requirements for risk credit, as well as the recommendation to adopt "Value at Risk" models within "Internal Ratings Based approaches". We intend to appraise the arguments raised by some analysts, according to whom Basle 2 shall bring harder conditions of access of banking resources to emerging economies.

Keywords: Basle 2, New Capital Accord, banking regulation, emerging economies.

Jell Classification: F33, G18.

1 Diretor executivo do Banco Mundial e professor do FEA-USP - email: ocanuto@worldbank.org

2 Professor livre-docente no FEA-Unicamp. email: almeidameirelles@uol.com.br 


\section{Introdução}

Em janeiro de 2001, o Comitê de Supervisão Bancária da Basiléia apresentou sua mais recente versão de proposta de um Novo Acordo de Capital, para ocupar o lugar do Acordo de 1988 firmado entre os supervisores bancários das economias avançadas (BIS, 2001). Originalmente desenhado para os bancos internacionalmente ativos dos países do G10, o Acordo acabou adotado por mais de 100 países, inclusive o Brasil. Sua eficácia foi erodida desde então, o que disparou sua reforma. $\mathrm{O}$ calendário dessa reforma, revisto em dezembro de 2001, prevê uma nova versão da proposta e outra rodada de consultas durante 2003, com finalização do Novo Acordo antes do fim do ano e sua implementação a partir de 2007.

O presente texto aborda algumas das implicações, para as economias emergentes, contidas na atual proposta de reformulação do Acordo de Capital da Basiléia. O trabalho propõe-se a utilizar uma versão simplificada da clássica análise de média-variância de seleção de portfólios, como referência, para examinar algumas das proposições que têm sido formuladas no corrente debate sobre o que vem se convencionando chamar de "Basiléia 2" ou "Novo Acordo de Capital".

$\mathrm{O}$ foco se dirigirá às duas orientações gerais mostradas no esboço de Basiléia 2: a maior sensibilidade a riscos na nova versão do "enfoque padronizado" de requisitos de capital para riscos de crédito e o uso de modelos de "Valor sob Risco" (Value at Risk - VaR) que deverá acompanhar o estímulo aos "enfoques com base em classificações internas de risco" (IRB). Alguns analistas têm apontado tais modificações como tendencialmente endurecedoras das condições de acesso de economias em desenvolvimento às finanças globais (e.g., Griffith-Jones e Spratt, 2001; Freitas e Prates, 2001).

A segunda seção recupera uma versão da "fronteira de eficiência" de portfólios, seguindo James Tobin, para um caso em que há 2 ativos de risco e um sem risco, com possibilidades de (des)alavancagem de portfólios através de aplicação/captação de recursos à taxa de juros sem risco. A partir daí, a seleçăo de portfólio é completada com duas regras de gestão de portfólio: 
na seção 3, adota-se uma regra de troca subjetiva entre risco e retorno, como expressão das preferências de investidores, na qual aparece como dado o grau de tolerância ao risco de um gestor de portfólio representativo; e

- a seção 4 aborda uma regra de restriçâo de perdas (ou de "prioridade para segurança" - safety first), como forma de representar a adoção de um modelo de VaR, classe de modelos recomendada pelo Comitê para os enfoques de IRB.

Finalmente, a seção 5 tenta ilustrar como alguns dos pontos de Basiléia 2, no que concerne a economias emergentes, podem ser abordados a partir do modelo presente nos itens anteriores. No tocante às alterações propostas pelo Novo Acordo para o "enfoque padronizado" de requisitos de capital da Basiléia, duas observações são destacadas, mediante referência à regra de troca subjetiva entre risco e retorno: (i) os efeitos realocativos, entre as próprias economias emergentes, do fim da distinção entre membros e não-membros da OCDE no peso do "risco soberano", além das demais modificações; e (ii) a acentuação do caráter prócíclico dos fluxos de capital para economias emergentes na prevista utilização de agências privadas de rating na estimativa deste "risco soberano".

Tenta-se também demarcar sob que condições a adoção de modelos de VaR, preconizada pelo Comitê, implica maiores restrições à exposição de portfólios no tocante aos ativos de economias emergentes. A conclusão é a de que o uso de modelos de VaR tende a ser restritivo em situações de alta tolerância ao risco, deixando de ser regra restritiva durante períodos de alta aversão ao risco pelos próprios investidores.

Por outro lado, caso um aumento na aversão ao risco se faça acompanhar por maior margem de segurança nos parâmetros do VaR, a pressão contra a alavancagem de portfólios e sua exposição a riscos de economias emergentes tende a ser amplificada. Por seu turno, maior tolerância aos riscos e menor margem de segurança no Var se reforçarão no que tange à alavancagem. Quanto maior a descentralização para o nível dos bancos na definição de parâmetros de segurança contra o risco, descentralização que tende a elevar a probabilidade de que as duas regras apontem para a mesma direção, maior tenderá a ser o caráter pró-cíclico da nova regulação. 


\section{A fronteira de eficiência de portfólios com alavancagem}

Em cada período, os gestores de portfólio baseiam-se em suas percepçōes da distribuição conjunta de retornos dos ativos. Suas posições, quanto aos ativos de risco, podem ser alavancadas a partir de empréstimos à taxa básica sem risco. Suponhamos que se trata de bancos universais, os quais podem recorrer a lançamento de títulos à taxa básica de juros sem risco, no mercado, ou a empréstimos junto ao banco central, para sustentar carteiras de ativos de risco com valor $(W)$ acima de seu capital próprio ( $V$ ). Alternativamente, podem decidir manter $W$ abaixo de $V$, aplicando o excedente com retorno de $r$ em títulos públicos.

Tem-se $W=V+B$, com $B$ representando dívidas assumidas, no caso de alavancagem $(B>0)$, ou aplicações sem risco no caso contrário $(B<0)$. Taxas de retorno são medidas em termos brutos, ou seja, $r$ (taxa de retorno do ativo sem risco) $=1+$ taxa de juros sem risco.

Há dois ativos com risco $(i=1,2)$, cujos retornos apresentam uma distribuição conjunta normal, conforme conjunto de informações processado pelos gestores. Suas médias são $\mu_{i}$, as variâncias denotadas por $\sigma^{2}{ }_{j}$ e sua covariância é dada por $\operatorname{cov}=$ $\rho . \sigma_{1} \cdot \sigma_{2}$, onde $\rho$ é o coeficiente de correlação $(-1 \leq \rho \leq 1)$ entre os dois ativos de risco. Supõe-se $\mu_{1}>\mu_{2}$ e $\sigma^{2}{ }_{1}>\sigma^{2}{ }_{2}$.

As variáveis de decisão alocativa de portfólio são as proporções dos ativos de risco $(W)$ e o nível de alavancagem: $B=$ - $W_{0} . V>0$, quando $W=\left(I-W_{o}\right) . V>V$ e vice-versa. Supomos ausência de efeitos de escala, o que permite a representação das carteiras a partir de tais proporções $\left(w_{0}+w_{1}+w_{2}=I\right)$ qualquer que seja o tamanho do portfólio. Cada investidor aloca uma unidade monetária de seu porffólio, num estado estacionário e em tempo contínuo.

O conjunto possivel de carteiras formadas apenas com ativos de riscos está mostrado na Figura 1, no espaço risco-retorno de portfólio $(\mu, \sigma)$, a partir de:

$$
\mu_{p}=x_{1} \cdot \mu_{1}+x_{2} \cdot \mu_{2} \text { e } \sigma_{p}=\left[x_{1}^{2} \cdot \sigma_{1}^{2}+x_{2}^{2} \cdot \sigma_{2}^{2}+2 \cdot x_{1} \cdot x_{2} \cdot \rho \cdot \sigma_{1} \cdot \sigma_{2}\right]^{1 / 2}
$$

1 O conteúdo a seguir condensa elementos já consolidados na literatura. Ver-se Elton e Gruber (1995), Houthakker e Williamson (1996) ou Alexander e Francis (1986). 
onde $x_{1}$ e $x_{2}$ valem para as proporções $w_{i}$ quando $w_{0}=0$. A Figura 1 inclui os dois casos extremos de $\rho$ igual $a+1 e^{o}-1$, além de um caso intermediário de correlação nula.

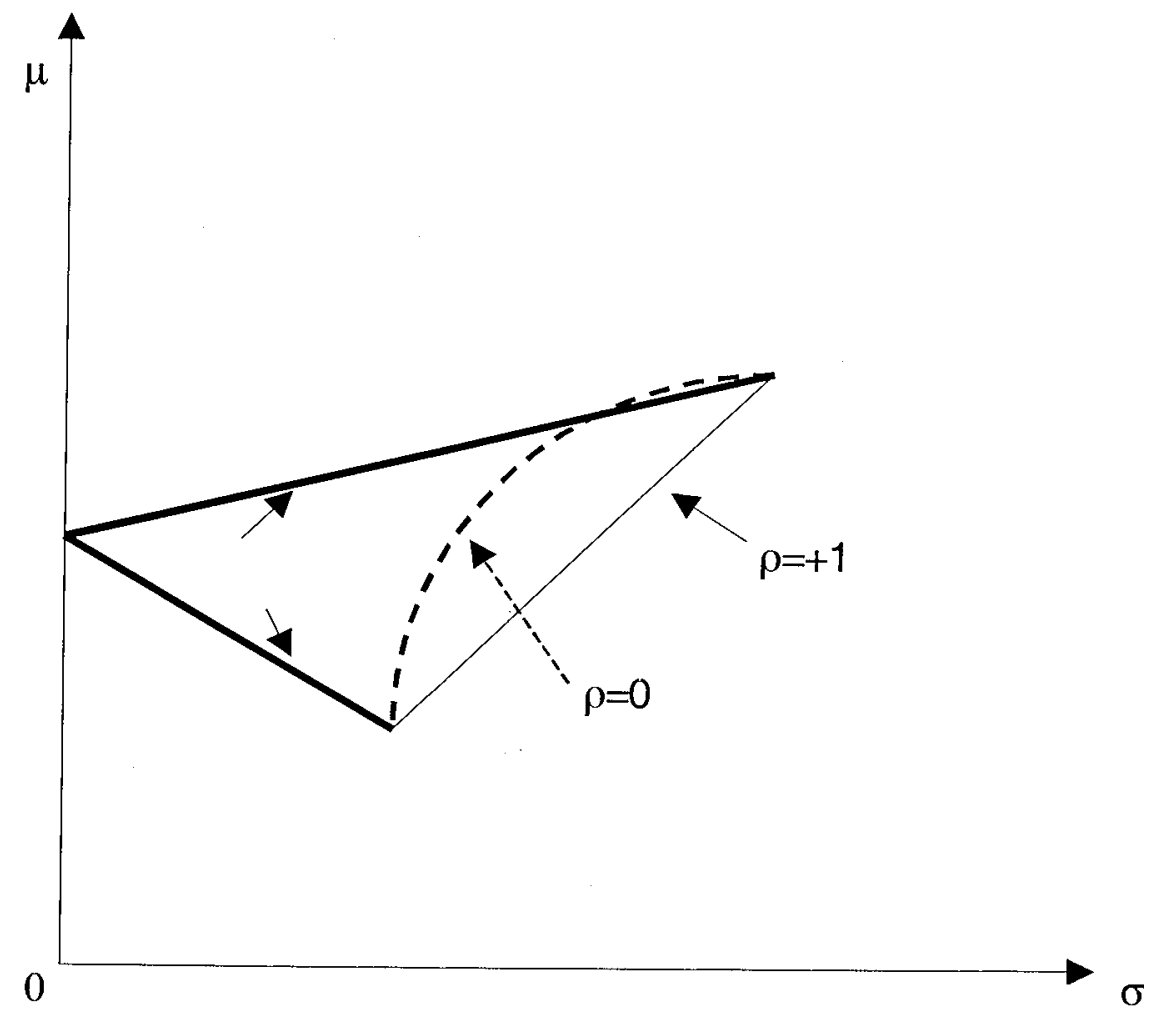

\section{Figura 1: Possibilidades de carteiras apenas com ativos de risco}

Qualquer uma das carteiras com ativos de riscos pode ser estendida ou encolhida linearmente através da (des)alavancagem (fazendo $W_{o}{ }^{1}$ o). Segue-se que a fronteira de eficiência de carteiras, ou seja, o conjunto de carteiras acessíveis com máximos $\mu^{\prime} s$ para cada nível de $\sigma$, para os casos de $-I<\rho<1$, é a linha reta:

(1) $\mu_{p}=r+\left[\left(\mu_{p}^{0}-r\right) / \sigma_{p}^{o}\right] \cdot \sigma_{p}$

onde $\mu_{p}^{o}$ e $\sigma_{p}^{o}$ valem para o portfólio de tangência, a saber, a carteira onde é máxima a inclinação de uma reta que, partindo de $r$, alcance o conjunto de possibilidades de portfólios de risco, 
conforme Figura 2. Para os casos extremos do coeficiente de correlação, aqui desconsiderados, um dos ativos de risco é excluído da fronteira de eficiência. A Figura 2 mostra a fronteira em algum caso de $-1<\rho<+1$.

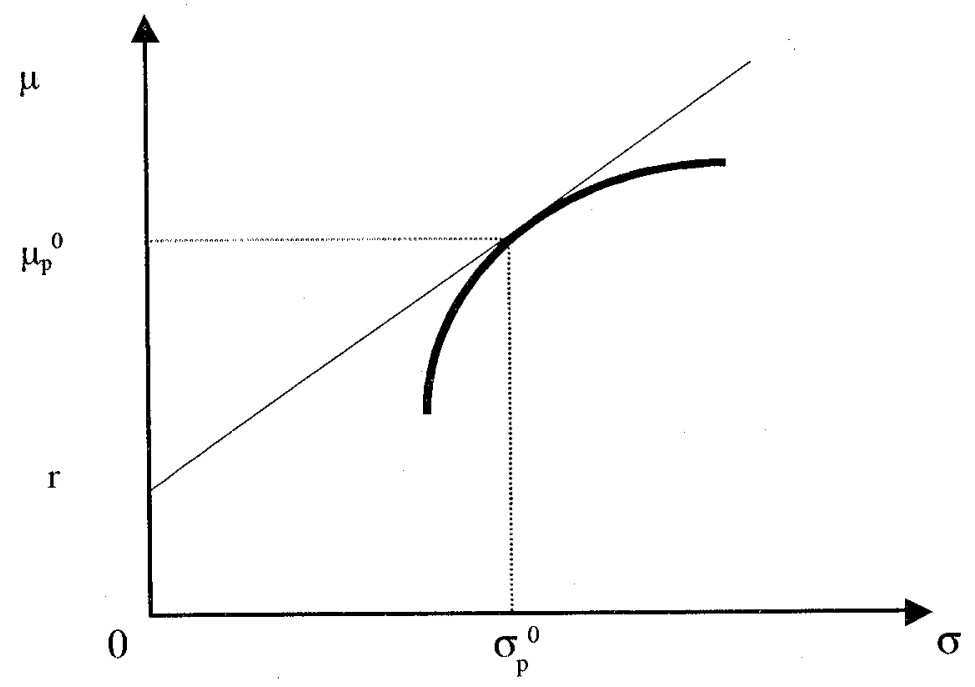

\section{Figura 2: Fronteira de eficiência de portfólios}

Obtém-se o portfólio de tangência a partir de:

(2) $\operatorname{Max} \theta=\left(\mu_{p}-r\right) / \sigma_{p}$ de onde:

(3a) $\chi_{1}^{0}=\left[\mu_{1}^{*} \cdot \sigma_{2}{ }_{2}-\mu_{2}^{*} \cdot \sigma_{I} \sigma_{2} . \rho\right] /\left[\mu^{*}{ }_{1} \cdot\left(\sigma_{2}^{2}-\sigma_{1} \cdot \sigma_{2} \rho\right)+\mu_{2}^{*} \cdot\left(\sigma^{2}{ }_{1}-\sigma_{1} \cdot \sigma_{2} \cdot \rho\right)\right]$

(3b) $\chi_{2}^{o}=\left[\mu_{2}^{*}, \sigma_{1}^{2}-\mu_{1}^{*} \cdot \sigma_{1} \sigma_{2} \cdot \rho\right] /\left[\mu_{1}^{*} \cdot\left(\sigma_{2}^{2}-\sigma_{1} \cdot \sigma_{2} \cdot \rho\right)+\mu_{2}^{*} \cdot\left(\sigma_{1}^{2}-\sigma_{1} \cdot \sigma_{2} \cdot \rho\right)\right]$ nos quais $\mu^{*}{ }_{1}=\mu_{1}-r$ e $\mu_{2}^{*}=\mu_{2}-r$.

Chamemos de $D$ ao denominador comum a ambas (3a) e (3b), bem como $N_{1}$ e $N_{2}$ para os correspondentes numeradores. Tem-se, pois:

(3c) $\mu_{p}^{*}=\mu_{p}^{0}-r=\left[\mu_{1}^{*} \cdot N_{1}+\mu_{2}^{*} \cdot N_{2}\right] / D$

(3d) $\sigma_{p}^{2 o}=\left[\mu_{p}{ }^{*} . S\right] / D$ onde $S=\left(1-\rho^{2}\right) \cdot \sigma^{2}{ }_{r} \sigma^{2}{ }_{2}>0$

A fronteira de eficiência corresponde aos pontos sobre:

(3e) $\mu=r+\left[\left(\mu^{*}, N_{1}+\mu^{*}{ }_{2} \cdot N_{2}\right) / \mathrm{S}\right]^{1 / 2} \cdot \sigma$

$\mathrm{Na}$ verdade, para qualquer ponto sobre a fronteira de eficiência, ao qual corresponda um certo $\mu=\mathrm{k}$ e um $\sigma=\sigma^{k}$, tem-se:

$$
(\mathrm{k}-\mathrm{r}) / \sigma^{k}=\mu_{p} * / \sigma_{p}^{o} \text { onde }(\mathrm{k}-\mathrm{r}) / \mu_{p}^{*}=\left(1-w_{o}\right)
$$


Pode-se extrair, então:

(4a) $\left.\mathrm{w}_{1}=\left[(\mathrm{k}-\mathrm{r}) / \mu_{\mathrm{p}}{ }^{*}\right)\right] \cdot \chi_{1}^{0}=\left(1-\mathrm{w}_{0}\right) \cdot \chi_{1}^{0}$

(4b) $\left.w_{2}=\left[(k-r) / m_{p}^{*}\right)\right] \cdot \chi_{2}^{0}=\left(1-w_{0}\right) \cdot \chi_{2}^{0}$

Sabemos também que:

(5) $\mathrm{k}=\left[1-\left(\mathrm{w}_{1}+\mathrm{w}_{2}\right)\right] \cdot \mathrm{r}+\left(\mathrm{w}_{1}+\mathrm{w}_{2}\right) \cdot \mu_{\mathrm{p}}^{0}=\mathrm{w}_{0} \cdot \mathrm{r}+\left(1-\mathrm{w}_{0}\right) \cdot \mu_{\mathrm{p}}^{0}$

(6) $\sigma_{k}^{2}=\left(w_{1}+w_{2}\right)^{2} \cdot \sigma_{p}^{20}=\left(1-w_{0}\right)^{2} \cdot \sigma_{p}^{20}$

3 Regra de troca subjetiva entre risco e retorno

$O$ investidor representativo tem preferências quanto a risco e retorno com uma Constante Aversão Relativa ao Risco. Seu comportamento pode ser descrito por: ${ }^{2}$

(7) $\operatorname{Max} \mu-(1 / 2) \cdot \tau \cdot \sigma^{2}$ sob a restrição de que o portfólio esteja na fronteira de eficiência.

$\tau>0$ é o indicador do grau de tolerância ao risco (decorrente da Constante Aversão Relativa ao Risco). Quanto maior o $\tau$ (maior a aversão ao risco), maior será a intensidade em que o retorno tem que compensar elevações no risco da carteira, para manter o nível de bem-estar. A Figura 3 ilustra dois mapas de indiferença para $\tau^{\prime}>\tau^{\prime}$.

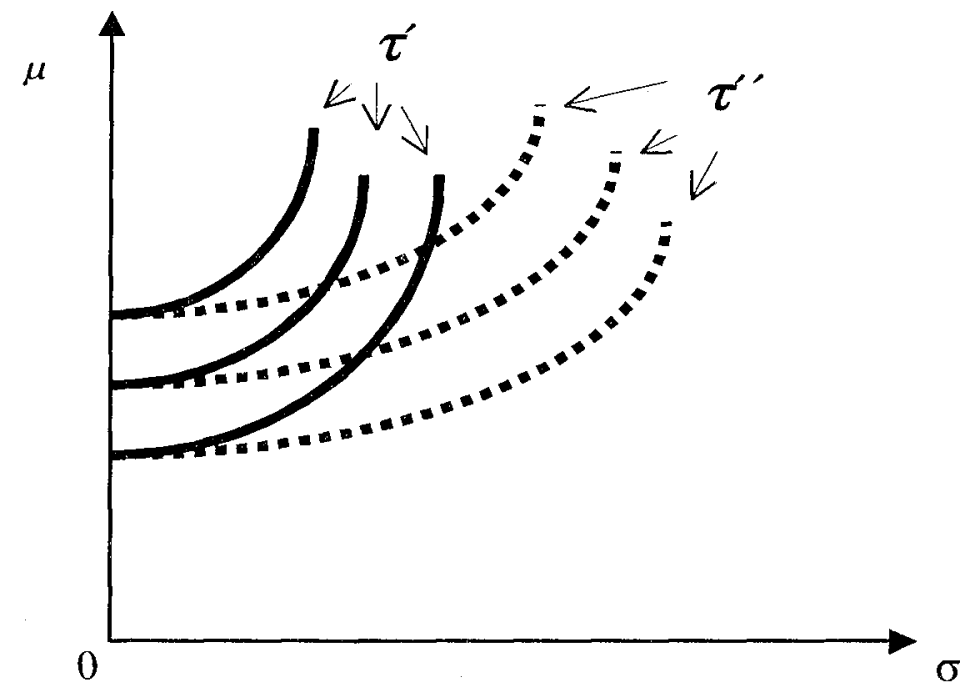

\section{Figura 3: Tolerâmeia ao risco}

2 Ver demonstrações nos livros-texto citados na nota anterior. 
A partir de (5) e (6), a regra (7) transforma-se em (com $w_{o}$ variável):

(8) $\operatorname{Max} Z=\operatorname{Max}\left[w_{o} \cdot r+\left(1-w_{o}\right) \cdot \mu_{p}^{o}\right] \cdot(1 / 2) \cdot \tau \cdot\left(1-w_{o}\right)^{2} \cdot \sigma_{p}^{2 o}$

O nível de alavancagem $\left(-w_{o}>0\right)$ será aquele ao qual $\mathrm{dZ} / \mathrm{dw}_{0}=0$, ou seja:

(9) $\left(1 \cdot w_{0}\right)=\left(w_{I}+w_{2}\right)=\left(\mu_{p}^{o}-t\right) /\left(\tau \cdot \sigma_{p}^{20}\right)=\mu_{p}^{*} /\left(\tau \cdot \sigma_{p}^{2 o}\right)$

De (3c)-(3d), (4a)-(4b) e (9), alcançamos as demandas pelos ativos 0,1 e 2 por unidade monetária:

(10a) $W_{I}=N_{1} /(\tau . \mathrm{S})=\left[\mu^{*}{ }_{1}, \sigma^{2}{ }_{2}-\mu^{*}{ }_{2} \cdot \sigma_{1} \cdot \sigma_{2} \cdot \rho\right] /\left[\mathrm{t} .\left(1-\rho^{2}\right) \cdot \sigma^{2}{ }_{1} \sigma^{2}{ }_{2}\right]$

(10b) $w_{2}=N_{2} /(\tau . \mathrm{S})=\left[\mu^{*}{ }_{2} \cdot \sigma^{2}{ }_{1}-\mu^{*}{ }_{1}, \sigma_{I} \sigma_{2}, \rho\right] /\left[\mathrm{t} .\left(1-\rho^{2}\right) \cdot \sigma^{2}{ }_{I} \sigma^{2}{ }_{2}\right]$

Como seria de se esperar, quanto menor a aversão ao risco nas preferências do investidor, maiores são as quantidades demandadas por 1 e 2 e, portanto, maior a alavancagem. A Figura 4 ilustra duas situações de equilíbrio, uma com alavancagem $\left(\mathrm{A}^{0}\right)$ e outra com desalavancagem $\left(A^{1}\right)$, refletindo respectivamente um baixo nível de aversão ao risco (pequeno valor de $\tau$ ) e outro elevado (valor alto de $\tau$ ). Comparando (10a)-(10b) e (3a)-(3b), observa-se que o limiar entre alavancagem e desalavancagem - o grau de aversão ao risco tal que a escolha recai sobre o portfólio de tangência - corresponde a:

$\tau=\mathrm{D} / \mathrm{S}$

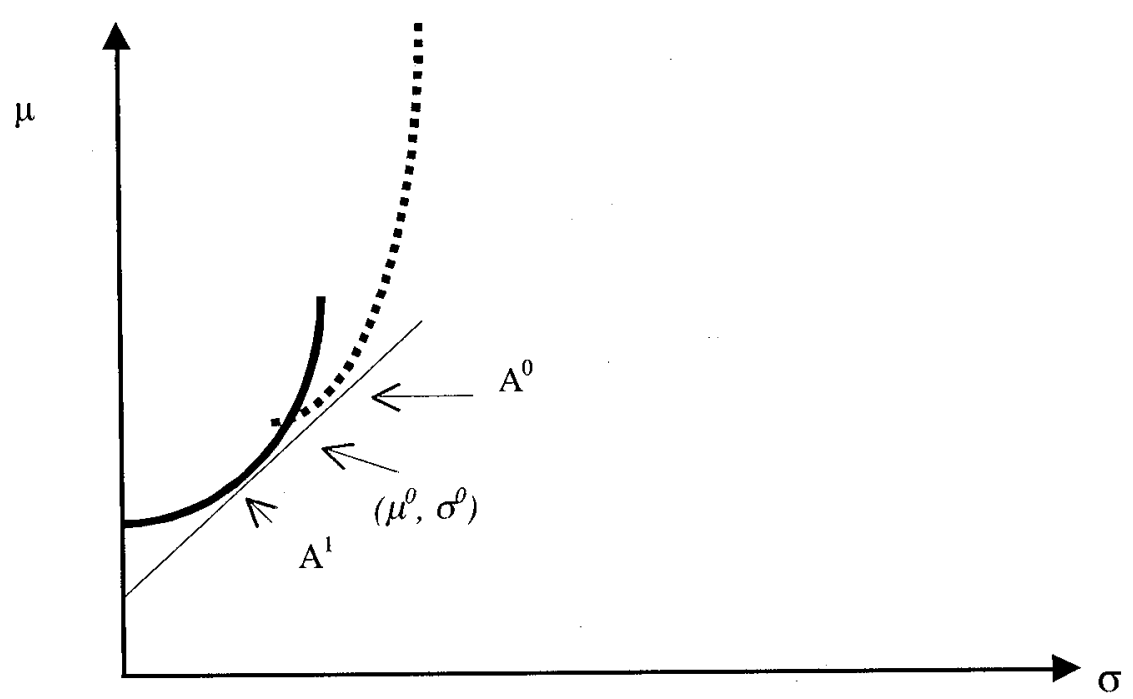

Figura 4: Equilibrio de portfólio e aversão ao risco 
Um resultado trivial é o de que as demandas pelos ativos respondem positivamente, cada uma, a elevações em seus diferenciais de retornos em relação à taxa de juros do ativo sem risco.

(11a) $\mathrm{d} w_{1} / \mathrm{d} \mu^{*}{ }_{1}=\sigma^{2}{ }_{2} /\left[\tau \cdot\left(1-\rho^{2}\right) \cdot \sigma^{2}{ }_{1} \sigma^{2}{ }_{2}\right]>0$

(11b) $\mathrm{d} w_{2} / \mathrm{d} \mu_{2}{ }_{2}=\sigma^{2}{ }_{1} /\left[\tau \cdot\left(1-\rho^{2}\right) \cdot \sigma_{r}{ }_{r} \sigma_{2}^{2}\right]>0$

Por outro lado, o efeito sobre o ativo concorrente dependerá da correlação entre os retornos ser positiva ou negativa:

(11C) $\mathrm{d} w_{I} / \mathrm{d} \mu^{*}{ }_{2}=\mathrm{d} w_{2} / \mathrm{d} \mu^{*}{ }_{1}=-\rho /\left[\tau \cdot\left(1-\rho^{2}\right) \cdot \sigma_{1} \cdot \sigma_{2}\right]$

Haverá queda (aumento) na quantidade demandada de um ativo, diante de elevação no retorno do substituto, caso a correlação seja positiva (negativa). Simetricamente, caso a correlação seja negativa, aparece a possibilidade de uma espécie de contágio, pelo qual uma queda no retorno de um ativo provoca redução também na quantidade demandada do outro ativo, com o efeito-substituição sendo superado, mesmo sem mudança nos fundamentos do ativo contagiado.

O impacto da subida no retorno de um dos ativos sobre a alavancagem também dependerá do sinal da correlação. Para níveis suficientemente altos de correlação positiva, o aumento no retorno de um ativo poderá até provocar redução de alavancagem do portfólio, caso a redução na quantidade demandada do ativo substituto seja ainda maior, em termos absolutos, do que o incremento na própria demanda do ativo cujo retorno aumente:

(11d) $\mathrm{d}\left(W_{1}+w_{2}\right) / \mathrm{d} \mu_{1}^{*}=\left[\sigma^{2}{ }_{2}-\rho \cdot \sigma_{r} \sigma_{2}\right] /\left[\tau \cdot\left(1-\rho^{2}\right) \cdot \sigma_{r}^{2} \sigma_{2}^{2}\right]$

(11e) $\mathrm{d}\left(w_{1}+W_{2}\right) / \mathrm{d} \mu_{2}^{*}=\left[\sigma^{2}{ }_{1}-\rho \cdot \sigma_{T} \sigma_{2}\right] /\left[\tau \cdot\left(1-\rho^{2}\right) \cdot \sigma_{T}^{2} \sigma^{2}{ }_{2}\right]$

A derivada (11d) será $<0$ caso $\rho>\left[\sigma^{2}{ }_{2} / \sigma_{r} \cdot \sigma_{2}\right]$, enquanto (11e) também será negativa quando $\rho>\left[\sigma^{2} / \sigma_{I} \cdot \sigma_{2}\right]$. Como supomos $\mu_{1}>\mu_{2}$ e $\sigma_{1}^{2}>\sigma_{2}^{2}$ é mais provável que $\rho>\sigma^{2}{ }_{2} / \sigma_{I} \cdot \sigma_{2}$ do que $\rho>\sigma^{2}{ }_{1} / \sigma_{i} . \sigma_{2}$.

Note-se, por outro lado, que, a partir de (10a)-(10b), a soma das parcelas de 1 e 2 pode ser vista como:

(12) $W_{I}+W_{2}=\left[\mu_{1}^{*} \cdot\left(\sigma_{2}^{2}-\sigma_{T} \sigma_{2} \rho\right)+\mu_{2}^{*}\left(\sigma_{2}^{2}-\sigma_{T} \sigma_{2} \rho\right)\right] /\left[\tau \cdot\left(1-\rho^{2}\right) \cdot \sigma_{T}^{2} \sigma_{2}^{2}\right]>0$

Portanto, apenas uma entre as derivadas (11d) e (11e) pode vir a ser negativa. 
Note-se também que a intensidade de cada um dos efeitos será tão maior quanto mais baixo for o grau de aversão ao risco (baixo $\tau$ ). A sensibilidade das decisões quanto à alavancagem $e$ a quanto à alocação relativa entre os ativos de risco, diante de mudanças nos retornos desses ativos, será exacerbada quando for mais elevada a tolerância dos agentes perante o risco.

\section{Regra de restrição de perdas}

Em lugar da otimização dentro do trade off entre risco e retorno, há também uma classe de regras de gestão que quantificam e restringem o risco para baixo nos portfólios. Embora hoje em dia sejam desenvolvidas e crescentemente adotadas dentro da família de modelos de gestão de risco a partir do "Valor sob Risco" (VaR), suas origens remontam às regras de "prioridade para segurança" (safety first rule) presentes na literatura de finanças desde os anos 1950.

A regra básica é maximizar o retorno esperado do capital investido, com uma restrição sobre a probabilidade máxima de que as perdas potenciais superem algum nível especificado: (13) $\operatorname{Max}$ m sujeito à restrição de que $\operatorname{Prob}\left[\mu_{p}<\mu^{m}{ }_{p}\right] \leq z$

Onde $\mu^{m}{ }_{p}$ significa certo patamar mínimo de rentabilidade e $0<\mathrm{z}<1$ é a probabilidade de que o retorno do portfólio fique abaixo de tal patamar. A regra diz que deve haver, no máximo, uma probabilidade de $z \%$ de que o valor do portfólio finde abaixo de $\mu^{m}{ }_{p}$ por unidade de capital investido (o "valor sob risco").

Dado que os retornos dos ativos estão distribuídos normalmente, a restrição corresponde a:

(13a) $\mathrm{E}\left(\mu_{p}\right) \geq \mu_{p}^{m}+\mathrm{n} \cdot \sigma_{p}$

onde $\mathrm{n}$ é obtido diretamente de $\mathrm{z}^{3}$ Como os retornos estão normalmente distribuídos, a probabilidade de que o retorno obtido venha a ficar abaixo de certo nível depende do número de desvios-padrão abaixo da média em que está aquele nível. Da tabela da distribuição normal sabemos, por exemplo, que $z=5 \%$ implica $n=1,65$ desvios-padrão, enquanto $z=2,5 \%$ corresponde a $n=1,96$.

Em nosso contexto de alavancagem, deve-se observar que $\mu_{p}^{m}<r$, bem como que $\mathrm{n}>\mu_{\mathrm{p}}{ }^{0} / \sigma_{\mathrm{p}}{ }^{0}$, para que se tenha 3 A rigor, as restriçōes também são equivalentes em casos de outras distribuições não normais (Elton e Gruber, 1995). 
soluções interiores. Como se pode ver na Figura 5, se $\mu_{p}^{m} \geq r$ e/ou $n \leq \mu_{\mathrm{p}}{ }^{0} / \sigma_{\mathrm{p}}{ }^{0}$ haverá aquisição nula ou infinita de ativos de risco. No caso da reta I, demarcando acima dela a área permitida, a demanda por ativos de risco vai ao infinito. Por seu turno, no caso da reta III, não há portfólio de risco capaz de atender à restrição. $\mathrm{Na}$ reta $\mathrm{IV}$, mais uma vez a regra se torna compativel com alavancagem infinita.

$\mathrm{O}$ ponto $\mathrm{P}^{0}$ é o portfólio que tende a ser escolhido na regra em questão. Tomando a restrição (13a) como equação e igualando-a à equação (1), tem-se:

$$
\begin{aligned}
& r+\left[\left(\mu_{p}^{0}-r\right) / \sigma_{p}^{0}\right] \cdot \sigma_{p}=\mu_{p}^{m}+n \cdot \sigma_{p} \\
& \sigma_{p}^{p}=\left[\mu_{p}^{m}-r\right] \cdot \sigma_{p}^{0} /\left[\mu_{p}^{*}-n \cdot \sigma_{p}^{0}\right]
\end{aligned}
$$

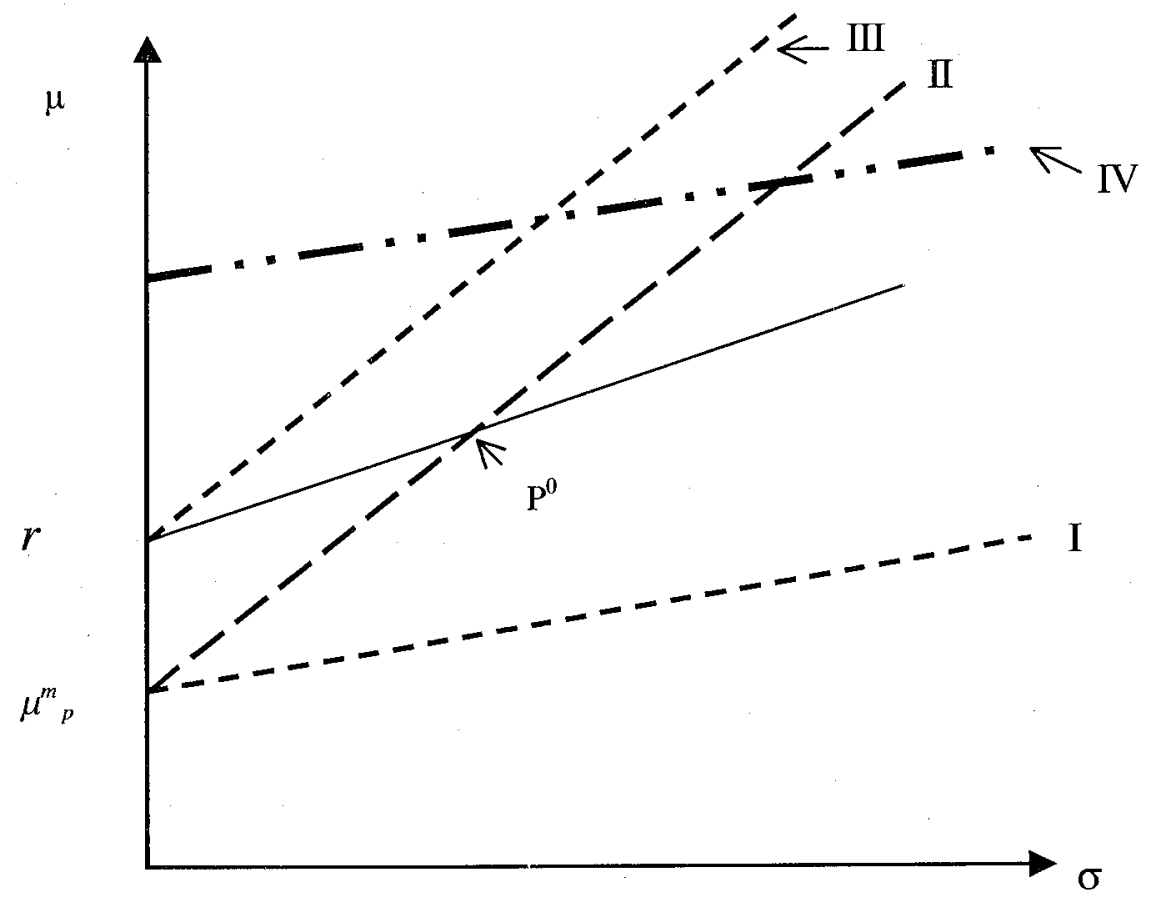

Figura 5: Fronteîra de eficiência e restrição de perdas

$\sigma_{p}^{p}$ refere-se ao desvio padrão da carteira escolhida. Observe que $\mu_{p}^{p}<\mathrm{r}$ bem como $\left(\mu^{*}{ }_{p} / \sigma_{p}{ }^{9}\right)<\mathrm{n}$ são condições necessárias para que a solução (15) seja positiva e significativa, conforme mencionamos acima. 
Por seu turno, o retorno esperado do portfólio escolhido será: (16) $\mu_{\mathrm{p}}^{\mathrm{p}}=\mu_{\mathrm{p}}^{\mathrm{m}}+\mathrm{n} \cdot \sigma_{\mathrm{p}}^{0} \cdot\left[\mu_{\mathrm{p}}^{\mathrm{m}}-\mathrm{r}\right] /\left[\mu_{\mathrm{p}}^{*}-\mathrm{n} \cdot \sigma_{\mathrm{p}}^{0}\right]$

Saberemos se a regra de restrição a perdas implicará desalavancagem ou não mediante comparação entre $\sigma_{p}^{p}$ e $\sigma^{o}{ }_{p^{\prime}}$ ou seja, haverá alavancagem caso o primeiro seja maior que $p^{\prime}$ segundo, o que ocorrerá se:

\section{(17) $r-\mu_{p}^{m}>\left[n . \sigma_{p}^{0}-\mu_{p}^{*}\right]$}

A propensão a refrear a alavancagem dependerá do grau de segurança preconizado na regra. Quanto menor a margem de perdas estabelecida (maior o n), mais forte será a restrição a portfólios alavancados. Da mesma forma, quanto maior o patamar de retorno mínimo estabelecido como limiar das perdas (maior $\mu_{p}^{\mathrm{m}}{ }_{\mathrm{p}}$ ), mais restritiva a regra será sobre a alavancagem.

Finalmente, outro resultado a registrar diz respeito à comparação entre os portfólios selecionados de acordo com as duas regras aqui abordadas. Sob que condições a regra de restrição a perdas tende a levar a níveis de alavancagem e de exposição aos riscos de portfólio menores que no caso da livre expressão do grau de tolerância ao risco?

A partir de (6) e (9), sabemos que o risco (desvio-padrão) do portfólio ótimo sob a regra de otimização dentro do trade off risco-retorno será:

(18) $\sigma_{\mathrm{p}}^{\mathrm{t}}=\left(1-\mathrm{w}_{0}\right) \cdot \sigma_{\mathrm{p}}^{0}=\left[\mu_{\mathrm{p}}^{*} /\left(\tau \cdot \sigma_{\mathrm{p}}^{0}\right)\right]$

Comparando-a com a equação (15), sabemos que a escolha conforme preferências será restringida caso $\sigma_{p}^{t}>\sigma_{p}^{p}$, isto é: (19) $\tau<\left[\mu_{\mathrm{p}}^{*} / \sigma_{\mathrm{p}}^{2}{ }^{0}\right] .\left[\left(\mathrm{n} \cdot \sigma_{\mathrm{p}}^{0}-\mu_{\mathrm{p}}^{*}\right) /\left(\mathrm{r}-\mu_{\mathrm{p}}^{\mathrm{m}}{ }_{\mathrm{p}}\right)\right]$

Quanto mais baixa a aversão ao risco, maior é a possibilidade restritiva da "prioridade na segurança".

Estende-se também o que foi dito acima sobre a restrição da regra de segurança sobre a alavancagem. A propensão a refrear a alavancagem desejada conforme as preferências dependerá do grau de segurança preconizado na regra de safety first. Quanto menor a margem de perdas estabelecida (maior o n), mais alta será a chance de que o portfólio desejado será impedido. Da mesma forma, quanto maior o patamar de retorno mínimo estabelecido como limiar das perdas (maior $\mu^{\mathrm{m}}{ }_{\mathrm{p}}$ ), mais restritiva a regra poderá ser sobre o portfólio ótimo conforme preferências quanto a risco e retorno. 
Conclui-se, portanto, que os limites relativos à alavancagem, nas duas regras, dependerão tanto dos parâmetros de segurança contra perdas estabelecidos, quanto do estado das artes na aversão ao risco dos investidores. Caso ocorra uma busca de maior segurança nas regras de gestão de portfólio imposta, por exemplo, pelos reguladores -, ao mesmo tempo em que se verifique um aumento na aversão ao risco pelos investidores, o efeito restritivo sobre a alavancagem e a exposição aos ativos de risco será acentuado.

Usaremos, a seguir, os resultados deste e do item anterior para abordar algumas das implicações potenciais de Basiléia 2 para economias emergentes, situadas em geral em vizinhanças de risco significativo na fronteira de eficiência das finanças globais.

\section{Basiléia 2 e economias emergentes}

O Acordo de Adequação de Capital da Basiléia, em 1988, estabeleceu um nível mínimo de $8 \%$ para a proporção entre o capital e o valor dos ativos dos bancos, como forma de garantir sua solidez e segurança. Foi motivado pela percepção de que a intensa concorrência estava induzindo os bancos internacionalmente ativos a assumir patamares baixos em tais reservas de capital, na busca de ampliação de suas parcelas de mercado.

$\mathrm{O}$ acordo original foi um marco, não apenas pela busca de harmonização regulatória, mas também pela distinção entre os tipos de ativos por risco. Estabeleceu a exigência de que bancos calculassem o capital mínimo total de $8 \%$ a partir dos ativos ajustados pelos riscos. Pelo menos metade teria de ser capital de nível 1 (capital próprio e reservas), com a faixa 2 de capital podendo conter, por exemplo, instrumentos híbridos de captação de recursos.

O total ajustado pelos riscos dos ativos (no e fora-do-balanço) foi definido como a soma ponderada de ativos conforme sua classificação de risco de crédito. Os ativos no balanço foram enquadrados em 4 grupos de risco $(0 \%, 20 \%, 50 \%$ e $100 \%)$, aplicando-se tais percentuais sobre seu valor para estabelecer-se quanto dos $8 \%$ teria de ter a contrapartida em capital.

Bancos, riscos soberanos e empresas não-bancárias foram definidos como classes distintas de peso de risco. Além disso, den- 
tro de cada uma dessas classes, distinção foi feita entre países membros e não-membros da OCDE e, também, conforme prazo de vencimento do crédito (curto e longo prazos). Títulos governamentais de países da OCDE mantidos nas carteiras, por exemplo, foram considerados de risco zero, enquanto créditos interbancários receberam o peso de $20 \%$. Na outra ponta, os créditos ao setor privado não-bancário tornaram-se computáveis em $100 \%$ de seu valor, para efeito da estimativa do capital mínimo de $8 \%$.

Adicionalmente, determinou-se a conversão de contratos contingentes (derivativos, cartas de crédito, garantias) negociados no balcão a um equivalente de crédito naquelas classes, multiplicando-se então pelo correspondente peso de risco. Os derivativos negociados em bolsas ficaram originalmente de fora, em decorrência do fato de que seus market makers assumem o risco de crédito. Posteriormente, em 1996, foi estabelecido o requisito de capital para cobertura dos riscos de mercado (riscos de perdas originados de movimentos nos preços de mercado).

Esta emenda de 1996 trouxe outras mudanças significativas. Criou uma faixa 3 de capital para a cobertura dos risos de mercado, facultando a inclusão, nesta faixa, de títulos de dívida subordinada com maturidade abaixo de dois anos. Mas a grande novidade foi a permissão de que os bancos usassem modelos internos próprios para determinar a carga de capital para cobrir o risco de mercado, como alternativa em relação ao modelo padronizado. Este define a carga de capital associada a cada posição, determinando a partir daí como agregar estas cargas em um montante de capital para cobrir o risco de mercado do conjunto. Já o chamado enfoque de modelos internos abriu a oportunidade de que os bancos manejassem modelos próprios para estimar o Valor sob risco, com o requisito de capital correspondente sendo obtido a partir da estimativa deste VaR.

A reforma no Acordo da Basiléia foi disparada pela erosão crescente de sua eficácia, apesar das emendas, particularmente por causa das práticas de arbitragem de capital regulatório (JONES, 2000). Estas são estratégias de redução de requisitos regulatórios de capital sem uma concomitante diminuição no grau de exposição a riscos. Por exemplo, a possibilidade de venda - ou outro deslocamento para fora do balanço - de ativos para os quais a avaliação, pelo banco, do capital adequado é menor do que a estabelecida pela regulação, deixando em carteira os ativos 
em situação oposta. A conseqüência tende a ser registros de capital/ativos regulatórios abaixo dos que seriam economicamente adequados. Mesmo quando os primeiros se mostram crescentes, a segurança pode ser ilusória.

As contínuas inovações financeiras - securitização de empréstimos, derivativos de crédito etc. - ampliaram o escopo para tais práticas. Na verdade, as principais direções nas mudanças financeiras recentes - securitização e consolidação financeira, globalização financeira e inovações financeiras - estenderam geográfica e setorialmente as oportunidades para manejo integrado dos riscos, pelos bancos, com decrescente separação entre bancos e não-bancos (CANUTO e LIMA, 2001). A arbitragem de capital regulatório seguiu-se como estratégia cada vez mais viável e relevante, particularmente na medida em que as novas tecnologias de mensuração de riscos, pelos bancos, permitiram maiores diferenças entre os requisitos por eles estimados como necessários e aqueles estabelecidos para ativos específicos pelos reguladores.

A consideração da heterogeneidade nos riscos dos ativos, no acordo original, buscou aproximar a regulação dos bancos à complexidade de suas operações. No entanto, não apenas seria impossivel reproduzir a complexidade e a heterogeneidade efetivas dos ativos e suas correlações, como a velocidade das transformações financeiras aumentou o descompasso entre essa complexidade e a diferenciação de riscos reconhecida no acordo.

A segunda grande insuficiência do acordo em vigor é o fato de não considerar as técnicas de atenuação de riscos (tais como a exigência de colaterais, o uso de derivativos e a securitização de ativos). Estaria, portanto, pecando por não premiar o uso e o aprimoramento de técnicas e instrumentos de gerenciamento de riscos.

O desenho para um Novo Acordo propôs-se a enfrentar tais insuficiências. Por um lado, no novo perfil para o "enfoque padronizado" (standardised approach), amplia o escopo da diferenciação de riscos, mediante maior detalhamento de classes de riscos de crédito e introdução de reserva específica para os riscos operacionais dos bancos, em adição ao tratamento de riscos de mercado, de taxas de juros e outros. A intenção é tornar os requisitos regulatórios de capital mais sensiveis no tocante aos riscos dos ativos, mesmo no caso do enfoque padronizado. 
A mudança maior, porém, está na inclusão de opções para o tratamento dos riscos de crédito. ${ }^{4}$ Para bancos menos habilitados a manejar sistemas sofisticados de avaliação e gestão de riscos, prevê a manutenção de pesos padronizados pelos supervisores para as classes dos ativos, com o recurso, contudo, a ratings efetuados por instituições externas aos bancos no caso de cada ativo: Alternativamente, dependendo de aprovação pelos supervisores, faculta a permissão de manejo, pelos bancos, de seus sistemas próprios de avaliação de riscos (Internal Risk Based Approaches - IRB), em dois níveis: foundation e advanced. A busca de alinhamento entre requisitos de capital regulatório e aqueles considerados adequados pelos próprios bancos seria reforçada pela transição do enfoque padronizado para os IRB.

O objetivo seria "eliminar a prática de manter-se dois conjuntos de registros, passando os parâmetros usados para cálculo do capital regulatório a ser os mesmos que a direção utiliza para gerir o banco. [...] À medida em que as técnicas de mensuração de risco melhorem, muitas serão incorporadas nas práticas de gestão bancária - mediante estimativas aperfeiçoadas de características de perdas - sem alteração na estrutura regulatória. A mudança e a inovação aperfeiçoarão o processo, ao invés de o enfraquecer." (MEYER, 2001).

A supervisão focalizaria, cada vez mais, a qualidade da gestão de riscos e a adequação de sua medida, além de alguns parâmetros mais gerais a ser observados. ${ }^{5}$ Além disso, a intenção manifesta na atual proposta de Basiléia 2 é a de que seja estabelecida uma estrutura de incentivos favorável à adoção dos IRB e a seu aprimoramento. O peso médio efetivo dos riscos para o banco como um todo deveria cair com os enfoques mais sofisticados, conforme a extensão da arbitragem de capital através deles alcançada. Portanto, tais bancos poderiam atingir encargos mais baixos de capital regulatório total e, assim, razões de capital com ponderação de riscos registradas como mais altas.

Dados os diferentes perfis de riscos seguidos nas estratégias dos bancos, individualmente, haveria maior variação nos novos requisitos de capital ajustados conforme riscos do que o observa-

${ }^{4}$ O tratamento dos riscos de mercado foi mantido. Como novidade, foi inzroduzida a cobertura de capital para o risco operacional.

5 Parafraseando Herbert Simon, uma regulação bancária cada vez mais "procedimental" e menos "substantiva" (CANUTO e LIMA, 2001). 
do hoje em dia. Por outro lado, a resposta dos bancos a mudanças em seus níveis de capital ponderados pelos riscos passaria a ser maior e mais rápida.

As principais dúvidas manifestas pelo público quanto a esse desenho - ver www.bis.org - durante o período de consultas no primeiro semestre de 2001, voltaram-se para o impacto das mudanças sobre a concorrência entre os grandes bancos e os demais:

- os requisitos dos enfoques IRB e a capacidade dos bancos para adotá-los;

- o impacto da cobertura do "risco operacional" e

- a estrutura de incentivos pró-IRB.

Contudo, devem ser destacadas as observações críticas quanto à possibilidade de que a aplicação generalizada de modelos de VaR leve a uma exacerbação de riscos sistêmicos (DANÍELSSON et al, 2001). Antes de tudo, a consideração de variâncias e covariâncias como exógenas não incorpora a possibilidade da endogeneidade dos riscos e da liquidez. Além disso, a possibilidade de emprego de técnicas de modelagem similares, pelos bancos, os tornaria mais homogêneos em suas estratégias e, por conseguinte, o sistema mais volátil e instável. Reconhecidamente, a simulação de cenários de stress e o recurso a modelos com distribuições de probabilidade não-normais não se constituíram, até aqui pelo menos, em soluções efetivamente suficientes para evitar tais problemas (FENDER e GIBSON, 2001).

Mesmo no nível simplificado da linearidade e normalidade das distribuições, como o da análise de média-variância aqui esboçada, em que as matrizes de variância e covariância são mantidas fixas na agregação dos comportamentos dos agentes, pudemos verificar a possibilidade de que, em momentos de aumento na aversão ao risco por parte de investidores, a tendência de queda na exposição ao risco seja exacerbada por aplicação de maior conservadorismo na regra do tipo VaR vigente. Este maior conservadorismo em relação a perdas potenciais pode ser movido pelos próprios bancos, pelos mesmos motivos da alteração nas preferências, ou pelos reguladores oficiais.

A rigor, a funcionalidade do VaR contra excessos na alavancagem e na exposição aos riscos seria maior justamente na situação oposta, atuando contra em momentos de otimismo e euforia, em que há elevação no grau de tolerância ao risco. 
Caso contrário, será o movimento para cima na exposição que será acentuado. E vice-versa em situações de encolhimento das finanças.

Este aspecto pró-cíclico de Basiléia 2 é uma de suas críticas mais freqüentes (OCAMPO, 2000). A conclusão é a de que, em lugar da descentralização máxima na adoção de estratégias de proteção contra perdas potenciais, os reguladores oficiais deveriam manejar contra-ciclicamente os parâmetros mais gerais da segurança contra riscos.

Aqui cabe nossa primeira observação sobre as economias emergentes. Como os ativos das economias emergentes se situam, em geral, nas zonas de maior risco, tendem a sofrer com maior intensidade tais efeitos pró-cíclicos de Basiléia 2, em seu atual desenho. Conforme vimos no item 2, a sensibilidade das decisões quanto aos ativos de risco, em termos de níveis de exposição e de revisão de posições, diante de mudanças nos retornos desses ativos, será exacerbada quando for mais elevada a tolerância dos agentes perante o risco. Depois de ciclos de expansão movidos por euforia, as conseqüências de notícias negativas quanto aos retornos săo mais pronunciadas, tornando a reversão súbita quando inflete a tendência na tolerância ao risco. Acrescente-se aí o fato de que, no caso de economias emergentes, a probabilidade das não-linearidades e riscos endógenos frisados por Daníelsson et al. (2001) é ainda maior, em decorrência da "fragilidade financeira" de suas economias.

Outro ponto de Basiléia 2 que tende a intensificar o caráter pró-cíclico das finanças globais, no que diz respeito às economias emergentes, é a proposta de recurso a agências privadas de rating na classificação de riscos soberanos. Por um lado, Basiléia 2 acabará com a distinção entre países de dentro e de fora da OCDE, algo que havia introduzido forte viés: por exemplo, a distinção entre os riscos soberanos do México e do Brasil, implicada pela inclusão do primeiro na OCDE, não é, na avaliação de riscos-país pelos mercados, tão grande quanto a incorporada na atual versão do acordo.

Hoje, o peso é de $0 \%$ para os países da OCDE e de $100 \%$ para os demais. Na nova versão de Basiléia, há 5 classes: (i) de $\mathrm{AAA}$ a $\mathrm{AA}-(0 \%)$; (ii) $\mathrm{A}+$ até $\mathrm{A}-(20 \%)$; (iii) $\mathrm{BBB}+$ até $\mathrm{BBB}-(50 \%)$; (iv) $\mathrm{BB}+$ até B- (100\%); e (v) abaixo de B- (150\%). Na ausência de rating, o encargo recebe o peso de $100 \%$. 
Por outro lado, a introdução oficial de agências de rating, como veículo para diferenciação de riscos soberanos, na proposta divulgada em janeiro de 2001, pode trazer outras distorções. Com efeito, a coleta e o processamento de informações são mais eficazes em nível de corporações do que no caso do risco soberano (REISEN, 2000). Dadas essas e outras dificuldades objetivas de estimativas de risco-país, estimativas que não são inclusive o principal produto comercial das agências privadas de rating, estas tendem a assumir um comportamento adaptativo e backwarding looking, ao invés de prospectivo e forward looking (LOYOLA, 2001).

Por isso, as reclassificações de risco soberano por essas agências se dão majoritariamente após a ocorrência de "notícias" positivas ou negativas quanto aos países, provocando assim rodadas adicionais de ajuste nas posições, quanto a ativos de risco, na mesma direção daquelas inicialmente ocorridas em nível dos investidores e de mercados. Em termos de nossa análise no item 2, as equações (11d) e (11e) ganham uma seqüência, na mesma direção original:

$$
\mathrm{d} w_{i} / \mathrm{d} \mu_{i}^{*}=f\left\{\sigma^{2}{ }_{j} /\left[\tau \cdot\left(1-\rho^{2}\right) \cdot \sigma_{i} \sigma_{j}\right]\right\} \operatorname{com} f^{*}>0
$$

Além disso, há um viés pró-maior rigor na estimativa de riscospaís das maiores economias emergentes, dado que, no caso a "punição" por um eventual excesso de zelo, é diminuta em relação ao "castigo" por demora no reconhecimento de tendências positivas (LOYOLA, 2001). A reputação de uma agência será mais danificada na hipótese de um erro de subestimação de risco em relação a um mercado emergente de maior tamanho e peso nos portfólios.

No que tange à reclassificação de riscos, dentro do enfoque padronizado, cabe destacar as modificações no tocante às classes de riscos associados a corporações e a bancos, dentro da orientação de reduzir o desalinhamento entre capital regulatório e riscos efetivos. Tanto no caso de bancos quanto no de corporações, o novo enfoque padronizado traz uma maior diferenciação por classes de rating.

Como exemplo de distorções criadas pelo desalinhamento embutido no atual acordo em vigor, podemos mencionar o peso de $20 \%$ dado aos empréstimos de curto prazo para economias emergentes, enquanto o crédito para bancos de fora da OCDE com vencimento acima de um ano recebe o encargo de $100 \%$ (isto é, $8 \%$ de seu valor têm de ser reservados como capital). Este viés 
pró-endividamento de curto prazo, contra um funding de maior horizonte temporal, esteve presente nas raízes da vulnerabilidade asiática em 1997-98 (CAILLOUX e GRIFFITH-JONES, 1998). A proposta de Basiléia 2 reduz o teto de curto prazo de seis para três meses, naqueles empréstimos da classe de $20 \%$.

Outra mudança significativa, para as economias emergentes, é a retirada do risco soberano como piso para a classificação de riscos de bancos e corporações. Serão beneficiadas particularmente as empresas locais - e as filiais de estrangeiras - que consigam boa classificação por agências de rating no exterior.

Para concluir este trabalho, podemos sublinhar as seguintes observações:

1. o impacto líquido das mudanças no enfoque padronizado, combinando mais classes para riscos (soberanos, bancários e corporativos) e eliminando algumas distorções provocadas por tipologias duais (OCDE e nāo-OCDE, curto e longo prazos), fica indefinido no caso das economias emergentes de posição próxima à linha de demarcação com as avançadas e definitivamente aponta para termos mais duros no caso das economias em desenvolvimento em escala inferior. $O$ alinhamento de riscos do capital regulatório com os riscos efetivos tende a punir as economias - e os agentes e instrumentos - de maior risco, até pela redução do viés a elas favorável presente nas atuais práticas de arbitragem de capital regulatório. $\mathrm{Na}$ perspectiva dos países, aumentaram os prêmios para a redução de riscos e a aproximação aos padrões das economias avançadas, sem que esta aproximação seja definida em termos de entrada na OCDE;

2. nos termos da atual proposta de Basiléia 2, a promoção dos IRB e do rating de riscos soberanos por agências privadas tende a reforçar o caráter pró-cíclico já potencialmente presente na regulação bancária no tocante às economias emergentes. Cabe observar, inclusive, que a punição ao risco, no contexto do foundation IRB, dependerá de parâmetros gerais quanto a probabilidades de inadimplência por classes de risco de crédito e outros ${ }^{6}$ e

${ }^{6}$ No caso, por exemplo, de riscos corporativos, Griffith-Jones e Spratt (2001, p.10) mostram como a proposta de aumento exponencial, e não linear, no peso dos riscos ao longo do conjunto de faixas de probabilidade de inadimplência, dentro do foundation IRB, tende a favorecer fortemente os empréstimos a empresas BBB ou mais. 
3. para as economias emergentes, mostra-se oportuno que busquem voz na definição de Basiléia 2, particularmente no que concerne aos fatores pró-cíclicos e aos parâmetros de segurança contra o risco. Supondo-se, é claro, que lhes seja de interesse suavizar a trajetória de adequação ao perfil de risco de economias desenvolvidas privilegiado na proposta de Basiléia 2.

\section{Referências bibliográficas}

ALEXANDER, G.J. e FRANCIS, J.C. (1986). Portfolio analysis, Prentice-Hall: N. Jersey. BIS (2001). Overview of the new Basel Capital Accord, Basel Committee on BankingSupervision, janeiro.

CAILLOUX, J. E GRIFFIT-JONES, S. (1998). Encouraging the long-term: institutional investors and emerging markets, Institute of Development Studies, Brighton, (mimeo.). CANUTO, O. E LIMA, G.T. (2001). "Regulação bancária no Mercosul". In: Baumann, R. (org.), Mercosul: avanços e desafios da integração, Brasilia: IPEA/CEPAL, (p. 323-395). DANíELSON, J. et al. (2001). An academic response to Basel II. LSE Financial Markets Group, Special Paper 130, maio.

ELTON, E.J. E GRUBER, M. (1995). Modern portfolio theory and investment analysis, N. York: John Wiley e Sons.

FENDER, I. e GIBSON, M.S. (2001). Stress testing in practice a survey of 43 major financial institutions, BIS Quarterly Review, Junho, (p. 58-62).

FREITAS, M.C.P. e PRATES, D. (2001). Sistema financeiro e desenvolvimento: as restriçōes das novas regras do Comitê da Basiléia para as economias emergentes, Jornada Nacional sobre o Desenvolvimento, Rio de Janeiro, agosto.

GRIFFIT-JONES, S. e SPRATT, S. (2001). Will the proposed new basel capital accord have a net negative effect on developing countries?, Institute of Development Studies, Brighton, (mimeo.).

HOUTHAKKER, H.S. e WILLIAMSON, P.J. (1996). The economics of financial markets. N. York: Oxford University Press.

JONES, D. (2000). Emerging problems with the Basel Accord: regulatory capital arbitrage and related issues, Journal of Banking and Finance, vol. 24, (p. 35-58).

LOYOLA, G. (2001). O acordo da Basiléia e os fluxos de capitais para o Brasil, Valor Econômico, 02 de julho, (p. A9).

MEYER, L.H. (2001). The New Basel Accord: challenges for banks and their supervisors, discurso na Risk Management Association, 17 de maio, (disponível no site do Federal Reserve).

OCAMPO, J.A. (2000). Developing countries' anti-cyclical policies in a globalized world, Temas de Coyuntura n. 13, Santiago: CEPAL, outubro.

REISEN, H. (2000). Revisions to the Basel Accord and sovereign ratings. In: Haussmann, R. E Hiemenz, U., (orgs.), Global finance from a Latin American viewpoint, Paris: OCDE. 